\title{
NOVAS EVIDÊNCIAS DE REMANESCENTES OCEÂNICOS NA FAIXA ARAÇUAÍ: AS ROCHAS META-ULTRAMÁFICAS DE SÃO JOSÉ DA SAFIRA*
}

\author{
Laurenn Wolochate Aracema ${ }^{1}$; Ana Carolina Neves ${ }^{1}$; Juliana Cristina Henriques Ferreira ${ }^{1}$; \\ Antônio Carlos Pedrosa-Soares ${ }^{1,2}$; Lydia Maria Lobato ${ }^{1,2}$; Carlos Maurício Noce ${ }^{1,2}$
}

\begin{abstract}
Neoproterozoic oceanic slivers have been characterized in the Araçuaí Belt, eastern Brazil. Close to the São José da Safira town, Minas Gerais State, meta-ultramafic rocks consist of serpentinite with preserved peridotite cores, talc-anthophyllite schists, a diopside-rich rock, and tremolite schist. They are closely associated with banded iron formation (magnetic oxide, sulfide and silicate types), muscovite schist and graphite schist. This rock assemblage is interpreted as an ophiolitic mélange emplaced by thrusts between two different units. One of them, correlated to the Salinas Formation, consists of quartz-mica schist (with garnet, staurolite, kyanite, and/or sillimanite), sedimentary-derived calc-silicate rock, and sparse orthoamphibolite. The unit correlated to the Capelinha Formation consists of orthoquartzite, hematite and mica quartzites. All described rocks were transported from NE to SW in response to a dextral, obliquethrust system. Geochemical data from metaultramafic rocks of São José da Safira indicate an ophiolitic origin. The comparison with data from other Neoproterozoic oceanic remnants (Abadiânia and Fuchuan) corroborates this interpretation.
\end{abstract}

\section{INTRODUÇÃO}

A presença de rochas meta-ultramáficas nos arredores de São José da Safira, cidade situada a nordeste de Governador Valadares (Fig. 1), foi indicada no mapa geológico escala 1:100.000 da Folha Santa Maria do Suaçuí (Silva 1997). Em função da descrição destas rochas ser muito semelhante à de remanescentes oceânicos anteriormente caracterizados na Faixa Araçuaí, esta área foi selecionada e mapeada em escala 1:25.000 por Neves e Ferreira (1999), e suas rochas meta-ultramáficas foram estudadas por Aracema (2000), no âmbito do projeto "Transectos Geoeconômicos do Nordeste Mineiro" (coordenado por A.C. Pedrosa Soares e financiado pela FAPEMIG).

O presente trabalho apresenta a caracterização geológica, petrográfica e geoquímica das rochas metaultramáficas que ocorrem nos arredores de São José da Safira (Fig. 2) e sua comparação geoquímica com rochas similares dos remanescentes oceânicos neoproterozóicos de Ribeirão da Folha (Faixa Araçuaí), Abadiânia (Faixa Brasília) e Fuchuan (China).

\section{OFIOLITOS NA FAIXA ARAÇUAÍ}

Ofiolitos são definidos como remanescentes de litosfera oceânica encaixados tectonicamente, através de falhamentos, nas margens continentais durante o processo orogênico (Gass 1990).

As sequências ofiolíticas completas, que são muito raras, representam a pilha estratigráfica da crosta oceânica (sedimentos de mar profundo, vulcânicas básicas, subvulcânicas básicas, sucessão máfica- ultramáfica acamadada) e a porção apical do manto superior (ultramáficas). Entretanto, a grande maioria das ocorrências ofiolíticas do planeta mostra associações desmembradas, parcial ou totalmente deformadas e alteradas por hidrotermalismo (e.g., Malpas et al. 1990, Sengupta et al. 1990, Dobretsov et al. 1992, Strieder e Nilson 1992a,b, Pedrosa-Soares et al. 1998, Vernikovskiy et al. 1998).

$\mathrm{Na}$ maior parte do Brasil, o intenso e profundo intemperismo químico é obstinado adversário da preservação da maior parte das rochas da pilha ofiolítica. Este fato dificulta muito a identificação de rochas máficas e ultramáficas, dentre elas aquelas que registram partes de edifícios ofiolíticos. Talvez seja esta uma razão do termo "ofiolito" ser frequentemente evitado no Brasil. No presente trabalho utilizamos expressões como "remanescente oceânico" no sentido da definição de ofiolito acima expressa.

Os remanescentes oceânicos neoproterozóicos da Faixa Araçuaí têm sido descritos desde o início da década de 90 (sínteses em Pedrosa-Soares e Wiedemann-Leonardos 2000, e Pedrosa-Soares et al. 2001). Sua mais sólida evidência de campo é uma associação metavulcano-sedimentar que, se completa, é constituída por quartzo-mica xisto, micaxisto e xisto peraluminoso (pelitos de mar profundo), com intercalações de formações ferríferas bandadas (tipos óxido, silicato e sulfeto), metachert, diopsidito sulfetado (um "exalito" cálcio-silicático-sulfetado), corpos de sulfetos maciços, grafita xisto, formação manganesífera (gondito), rocha cálcio-silicática (metassedimento pelito-carbonatado) e ortoanfibolito (metabasalto). Lascas de rochas meta-ultramáficas estão encaixadas 
nesta unidade metavulcano-sedimentar (Fig. 1).

O segmento setentrional desta unidade metavulcanosedimentar é a Fácies (ou Membro) Ribeirão da Folha, pertencente à Formação Salinas, cujos ortoanfibolitos representam metabasaltos com assinatura geoquímica de assoalho oceânico. Esta assinatura é correlacionável tanto a ambientes modernos quanto a ofiolitos neoproterozóicos. Os protólitos magmáticos destas rochas foram extraídos de manto empobrecido e se cristalizaram em torno de $800 \mathrm{Ma}$ (Pedrosa-Soares et al. 1998).
As lascas tectônicas de rochas meta-ultramáficas associadas à Fácies Ribeirão da Folha, nos arredores da localidade homônima, são constituídas predominantemente por tremolita xisto. Cromita é o único mineral magmático preservado. Os corpos de rochas meta-ultramáficas registram todas as estruturas tectônicas regionais, com destaque para a foliação dúctil principal e a lineação mineral nela contida. Dados isotópicos $\mathrm{Sm}-\mathrm{Nd}$ apontam para idade de cristalização magmática em torno de $800 \mathrm{Ma}$ (Carvalho et al. 1992, Pedrosa-Soares 1997).
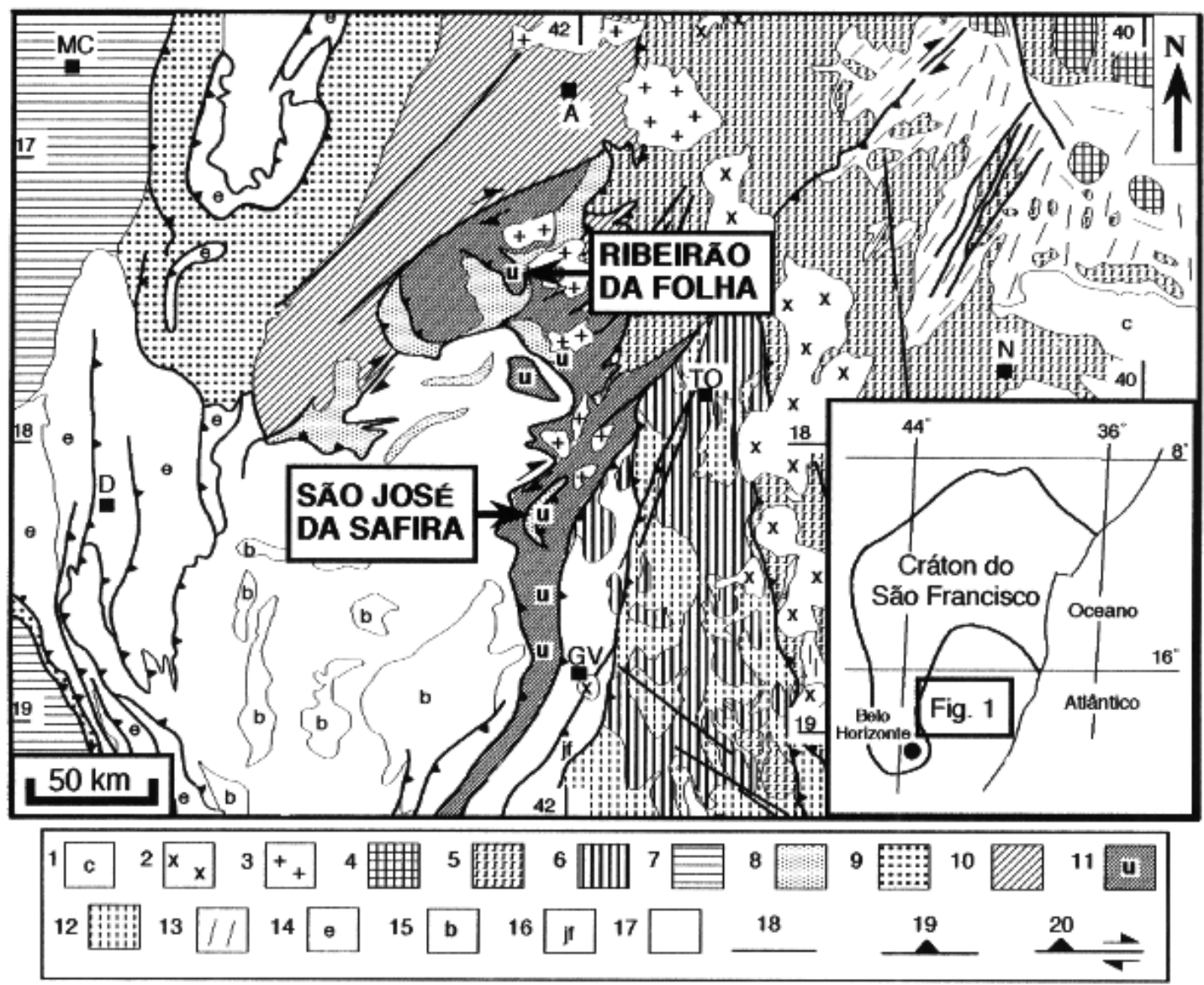

Figura 1: Localização dos corpos de rochas meta-ultramáficas de São José da Safira e Ribeirão da Folha no cenário geológico regional do setor central da Faixa Araçuaí (fonte: Pedrosa-Soares \& Wiedemann-Leonardos

2000). 1, coberturas cenozóicas. 2, Suíte G5: granitos tipo I pós-colisionais (520-500 Ma). 3, Suíte G4: granitos tipo S pós-colisionais (535-500 Ma). 4, Suíte G3-I: granitos tipo I tardi- a pós-colisionais (580-570 Ma). 5, Suíte G2 (granitos tipo S, gnaissificados, sin-colisionais, 590-575 Ma) e Suíte G3-S (leucogranitos peraluminosos, tardi- a pós-colisionais, 580-570 Ma). 6, Suíte G1: tonalitos e granodioritos pré- a sincolisionais (595-575 Ma). 7, Grupo Bambuí. 8, Formação Capelinha. 9, Grupo Macaúbas indiviso. 10,

Formação Salinas. 11, Seqüência Ribeirão da Folha-Dom Silvério: unidade metavulcanossedimentar de mar profundo, neoproterozóica, com assinatura MORB; $\boldsymbol{u}$, localização de corpos de rochas meta-ultramáficas. 12,

Grupo Rio Doce. 13, Complexo Jequitinhonha. Unidades pré-Neoproterozóicas: 14, Supergrupo Espinhaço;

15, Suíte Borrachudos; 16, Complexo Juiz de Fora; 17, complexos gnáissicos e restos de seqüências metavulcanossedimentares e metassedimentares associadas, de idades arqueanas e paleoproterozóicas. Falhas e zonas de cisalhamento: 18, indiscriminadas; 19, de cavalgamento ou descolamento; 20, de cavalgamento ou descolamento oblíquas.

Figure 1: Location of the meta-ultramafic rocks of São José da Safira e Ribeirão da Folha in the regional geologic scenario of the Faixa Araçuaí central sector (modified from Pedrosa-Soares \& Wiedemann-Leonardos 2000). 
Cunningham et al. (1998) sugerem que o Grupo Dom Silvério, situado na porção sudoeste da Faixa Araçuaí, também contém remanescentes oceânicos neoproterozóicos, correlatos da Fácies Ribeirão da Folha, representando assim o segmento meridional da unidade metavulcano-sedimentar portadora de corpos meta-ultramáficos similares aos de São José da Safira.

No mapa integrado da Faixa Araçuaí (Pinto et al. 1998, Pedrosa-Soares e Wiedemann-Leonardos 2000, Pedrosa-Soares et al. 2001), em parte representado na Figura 1, observa-se que a sequência Ribeirão da FolhaDom Silvério estende-se entre os paralelos $17^{\circ}$ e $21^{\circ}$ $\mathrm{S}$. Esta unidade é também evidenciada por marcantes anomalias magnéticas e gravimétricas (CPRM-SGA 1997, Molina et al. 2000).

Desta forma, os remanescentes de litosfera oceânica da Faixa Araçuaí delineam uma zona de sutura situada entre os paralelos $17^{\circ}-21^{\circ} \mathrm{S}$ e meridianos $42^{\circ}-43^{\circ} \mathrm{W}$, grosseiramente paralela ao arco magmático cálcioalcalino originado na Orogênese Brasiliana (Aracema et al. 1999, Pedrosa-Soares e Wiedemann-Leonardos 2000).

\section{GEOLOGIA DA ÁREA DE SÃO JOSÉ DA SAFIRA}

Esta área estrutura-se segundo direção geral N-S, sendo marcada por zonas de cisalhamento e falhas que mergulham para leste e limitam três unidades litoestruturais (Fig. 2).

A unidade A é constituída por ortoquartzito, quartzito ferruginoso fino e laminado, e quartzito micáceo. Esta unidade, que sustenta as formas de relevo mais elevadas da área, é correlata da Formação Capelinha (Grossi-Sad et al. 1997).

A Unidade B é caracterizada por rochas metassedimentares clásticas e formações ferríferas bandadas. As rochas metassedimentares clásticas são moscovita-quartzo xisto, portador eventual de biotita e/ou sillimanita e/ou granada, e xisto grafitoso, este composto por quartzo, mica e grafita. Formação ferrífera do tipo óxido é comum, sendo constituída por bandas ricas em magnetita alternadas com bandas quartzosas. Em menor quantidade ocorrem formações ferríferas dos tipos silicato e sulfeto. As do tipo silicato contêm bandas ricas em almandina e cummingtonitagrunerita alternadas com bandas quartzosas e, as tipo sulfeto, bandas ricas em pirita alternadas com bandas quartzosas.

Corpos de rochas meta-ultramáficas estão associados, no terreno, à unidade B. Macroscopicamente, distinguemse cinco litotipos ultramáficos: metaperidotito (rocha escura com manchas claras cinza-esverdeadas, com aparência similar a pele de cobra); talco-antofilita xisto (rocha de coloração branca-amarelada); serpentinito (rocha de granulação fina e coloração verde clara, com agregados radiais de antofilita); diopsidito (rocha de coloração verde-grama e grandes cristais euédricos de diopsídio em meio a quartzo e carbonato); tremolita xisto (rocha de granulação fina, verde escura, que se associa ao diopsidito).
Todas as evidências de campo sugerem que a unidade $\mathrm{B}$ representa uma mélange tectônica, na qual corpos meta-ultramáficos foram tectonicamente intercalados com metassedimentos clásticos e químicos.

A Unidade C é predominantemente constituída por xisto bandado, composto por biotita, quartzo, moscovita, granada, estaurolita, cianita e/ou sillimanita. O bandamento é caracterizado pela variação no conteúdo de quartzo. Bandas cálcio-silicáticas com porfiroblastos de anfibólio e granada são comuns. Intercalações de ortoanfibolito são raras. Esta unidade se correlaciona ao pacote de metassedimentos pelíticos de mar profundo da Fácies Ribeirão da Folha (Pedrosa-Soares et al. 1998).

A deformação dúctil é caracterizada por uma xistosidade plano-axial, dobras assimétricas apertadas a isoclinais e dobras em bainha, e pela lineação de estiramento mineral contida na xistosidade. A direção predominante da xistosidade é N20E, variando entre N20E e N50W na unidade C. Os mergulhos predominantes apontam para o hemisfério leste. As relações da lineação de estiramento com a xistosidade e diversos indicadores cinemáticos sugerem transporte tectônico oblíquo, de NE para SW, durante o estágio de deformação dúctil.

Nas rochas meta-ultramáficas a xistosidade pode estar mal desenvolvida, principalmente onde há preservação de minerais e texturas magmáticas, ou pode ser mascarada por recristalização tardia relacionada a hidrotermalismo. As rochas meta-ultramáficas, nos poucos afloramentos in situ, estão sobrepostas por falhas inversas aos quartzitos da Unidade A.

\section{PETROGRAFIA DAS ROCHAS ULTRAMÁFICAS}

É amplamente conhecido que as rochas ultramáficas apresentam (i) composição mineralógica primária essencialmente anidra, muito pouco estável sob as condições de metamorfismo e metassomatismo crustais, e (ii) que a sua composição química é, geralmente, muito contrastante com a composição química das rochas com as quais estão em contato.

Processos metamórficos-hidrotermais modificaram os minerais originais, pela introdução de $\mathrm{OH}^{-}$, gerando uma série de minerais hidratados. Como parte destes processos geralmente ocorre serpentinização. A existência de composição química contrastante induz o estabelecimento de gradiente químico entre a rocha ultramáfica e as rochas encaixantes, de modo que determinados componentes possam ser trocados entre estas rochas, de acordo com o contraste químico geral e com outras condições físico-químicas, como temperatura, pressão, fugacidade de oxigênio e pressão de fluido. Estas trocas de elementos definem a essência dos processos metassomáticos e podem resultar em arranjos de zonas minerais.

Estes dois conjuntos de processos de transformação geralmente se superpõem nas rochas ultramáficas, tornando difícil separar a influência de um ou de outro. 

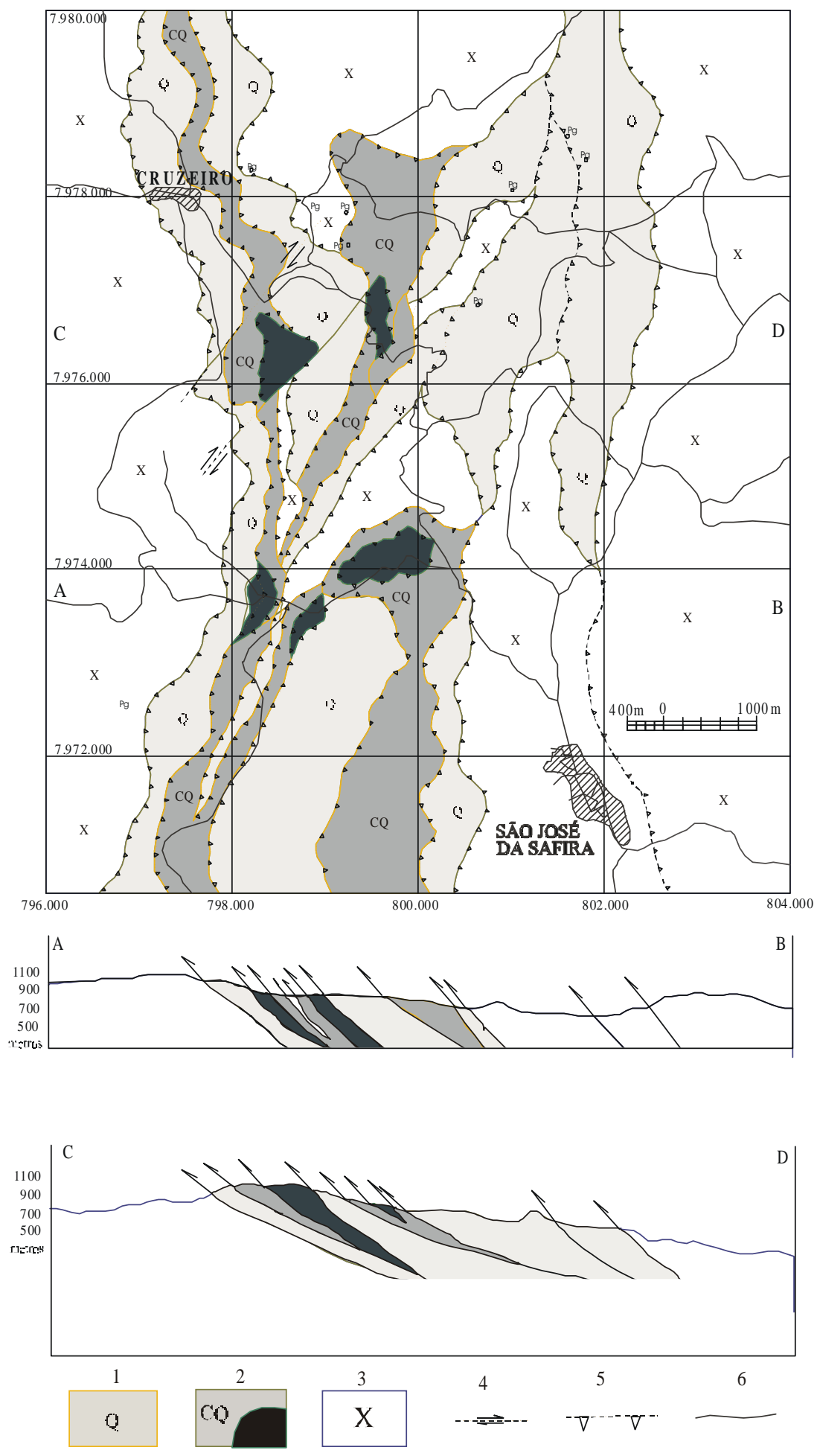

Figura 2: Mapa e perfis geológicos da região de São José da Safira (modificado de Neves \& Ferreira 1999). 1, unidade A (ortoquartzito, quartzito micáceo e quartzito ferruginoso). 2, unidade B, moscovita-quartzo xisto, xisto grafitoso e formações ferríferas bandadas; em negro representa-se corpos de rochas meta-ultramáficas tectonicamente alojados na unidade B. 3, unidade C, biotita xisto e quartzo-mica xisto, bandados, com intercalações de rochas cálcio-silicáticas e orto-anfibolito. 4, falha de rejeito direcional. 5, falha de empurrão (dentes no bloco cavalgante). 6, estradas. $A B$ e $C D$, orientações dos perfis.

Figure 2: Geologic map and sections of the São José da Safira area (modified from Neves \& Ferreira 1999). 1, unit A (orthoquartzite, micaceous quartzite and ferruginous quartzite). 2, unit B, moscovite-quartz schist, graphite schist and banded iron formations; in black are ilustrated bodies of meta-ultramafic rocks tectonicaly emplaced in unit B. 3, unidade $C$, banded biotite schist and quartz-mica schist wityh minor intercalations of calc-silicate rock and ortho-amphibolite. 4 , strike-slip fault. 5, thrust fault. 6 , roads. AB and CD indicate the geologic sections. 
Das rochas meta-ultramáficas encontradas na área de São José da Safira, foram estudados os quatro litotipos principais: metaperidotito, serpentinito, diopsidito e tremolita xisto.

As amostras de metaperidotito mostram variação no grau de alteração mineralógica e consequentemente, na preservação dos minerais e textura ígnea originais.

As amostras menos alteradas se caracterizam pela granulação grossa, apresentando restos dos minerais primários, como olivina e ortopiroxênio que aparecem sendo substituídos por serpentina, antofilita, talco e carbonato. Os cristais de olivina e de piroxênio encontram-se fraturados e a serpentina se desenvolve ao longo destas fraturas, caracterizando textura em malha (mesh) e bastita. Antofilita aparece em cristais aciculares. Talco forma grandes cristais euédricos, mas também ocorre na matriz, associado à serpentina que está geralmente orientada. Opacos e carbonato são frequentes. O último forma grandes cristais disseminados pela rocha.

No conjunto de amostras mais alteradas a olivina está totalmente substituída. A amostra mais alterada, entre os metaperidotitos, apresenta maior quantidade de serpentina e de antofilita, ausência de olivina e raro piroxênio. A deformação da antofilita é evidenciada pela extinção ondulante e presença de cristais encurvados. As quantidades de carbonato e opacos aumentam com o avanço da alteração.

O serpentinito se caracteriza pela predominância de serpentina, associada à antofilita, e pelos conteúdos subordinados de talco e clorita. A serpentina constitui fina matriz, fibrosa e marcantemente foliada, à qual se associam clorita e talco. Antofilita forma longos cristais aciculares, deformados, mas sem nenhuma orientação preferencial, tendendo a se arranjar em agregados fibroradiais.

O diopsidito é uma rocha muito rica em diopsídio e quartzo, com carbonato e algum anfibólio (antofilita). $\mathrm{O}$ bandamento desta rocha é dado por bandas ricas em diopsídio alternadas com bandas ricas em quartzo. A granulação varia desde porções com cristais de diopsídio que atingem um decímetro até porções de granulação milimétrica ricas em quartzo mas pobres em diopsídio.

Intercalado com o diopsidito ocorre tremolita xisto, que representa uma rocha quase monominerálica, composta por tremolita e raros opacos. O tremolita xisto apresenta granulação fina, textura nematoblástica, e xistosidade crenulada.

As seguintes associações minerais representam estágios diferentes na evolução das rochas metaultramáficas de São José da Safira:

- AM1 = olivina + piroxênio + cromita, que representa a composição mineralógica magmática, primária.

- AM2 = serpentina, representando a serpentinização da rocha original, por interação com fluido aquoso pobre em $\mathrm{CO}_{2}$, o que resultou na hidratação de olivina (olivina $+\mathrm{H}_{2} \mathrm{O} \rightarrow$ serpentina) e ortopiroxênio (ortopiroxênio + $\mathrm{H}_{2} \mathrm{O} \rightarrow$ serpentina). Este processo só ocorre sobre olivina e piroxênio, minerais da associação AM1, indicando tratar-se do primeiro estágio de alteração. A partir da serpentina formada neste estágio desenvolveram os minerais do estágio 3.

- AM3 = talco + carbonato + antofilita, que representa mudança para um sistema de fluido aquo-carbônico dominado por $\mathrm{CO}_{2}$, com reações como: serpentina + $\mathrm{CO}_{2} \rightarrow$ talco + carbonato; talco + carbonato $\rightarrow$ antofilita $+\mathrm{H}_{2} \mathrm{O}+\mathrm{CO}_{2}$; olivina + talco ${ }^{\circledR}$ antofilita $+\mathrm{H}_{2} \mathrm{O}$; olivina $+\mathrm{H}_{2} \mathrm{O}+\mathrm{CO}_{2} \rightarrow$ antofilita + carbonato; e ortopiroxênio $+\mathrm{H}_{2} \mathrm{O}+\mathrm{CO}_{2} \rightarrow$ antofilita + carbonato.

\section{GEOQUÍMICA DAS ROCHAS META- ULTRAMÁFICAS}

Os dados geoquímicos das amostras de rochas metaultramáficas de São José da Safira e de Ribeirão da Folha encontram-se em Aracema (2000). Os mesmos são comparados aos dados de corpos ultramáficos da mélange ofiolítica de Abadiânia, Faixa Brasília (Strieder \& Nilson 1992a,b) e do ofiolito de Fuchuan, China (Zou et al. 1995), ambos de idade neoproterozóica.

As rochas meta-ultramáficas de São José da Safira mostram ampla variação de conteúdos de elementos traços (Fig. 3a) e, no conjunto, são mais empobrecidas em elementos incompatíveis (Cs a Y), em relação às rochas meta-ultramáficas de Ribeirão da Folha (Fig. 3b). Entretanto, a composição média das amostras de São José da Safira aproxima-se do condrito de Evensen et al. (1978), enquanto as rochas meta-ultramáficas de Ribeirão da Folha são bem mais enriquecidas.

Harzburgitos e dunitos de ofiolitos apresentam conteúdos muito baixos de elementos terras raras, geralmente menores em relação ao condrito. Seus padrões de elementos terras raras normalizados para condrito tendem a ser mais empobrecidos nos elementos intermediários, delinenado a forma em $\mathrm{V}$ que é característica dos diagramas de harzburgitos e dunitos ofiolíticos (Henderson 1984).

Esta forma em V é notável nas amostras de São José da Safira, assim como, à exceção de uma amostra, o são os baixos conteúdos de elementos terras raras (Fig. 3c). Do mesmo modo, o padrão em $\mathrm{V}$ se destaca na representação das rochas meta-ultramáficas de Abadiânia (Fig. 3d).

Os conteúdos de elementos terras raras, principalmente das terras raras leves, são bem mais elevados nas amostras de Ribeirão da Folha (Fig. 3d). Isto pode se dever à generalizada alteração hidrotermal que afetou estas rochas (Carvalho et al. 1992) e/ou refletir outros fatores, tais como composição menos máfica devido a processos resultantes de cristalização fracionada e/ou de diferenciação cumulática. Os xistos ultramáficos de Ribeirão da Folha seriam derivados, principalmente, de piroxenitos ricos em cálcio (PedrosaSoares 1997).

Neste sentido, o ofiolito de Fuchuan é particularmente interessante para comparação, já que contém piroxenito que representa cumulados 
ultramáficos, além de peridotitos (Fig. 3d). Os resultados de elementos de terras raras das amostras de São José da Safira e Abadiânia e dos peridotitos de Fuchuam localizam-se no campo dos peridotitos
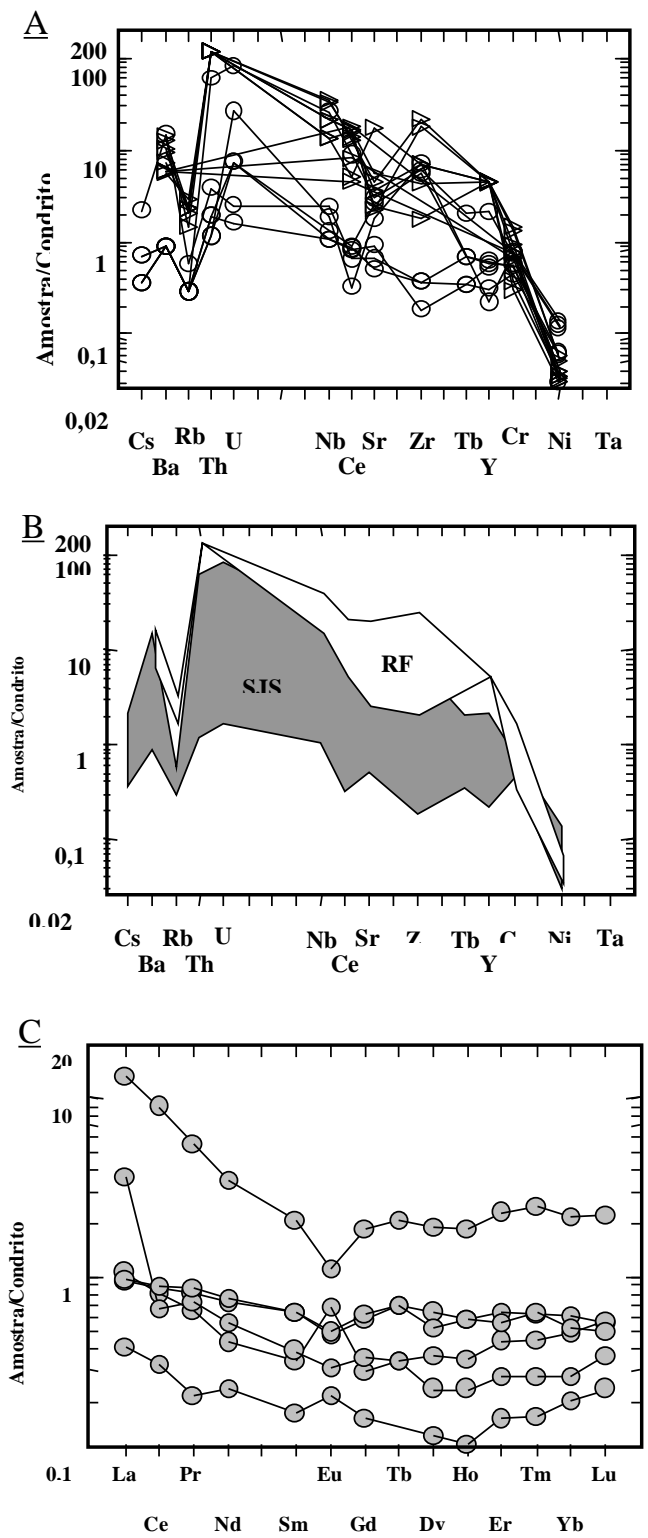

metamórficos de ofiolitos, enquanto que as de Ribeirão da Folha, estão no campo dos cumulados ultramáficos de ofiolitos, tal como as amostras de piroxenito de Fuchuam (Fig. 3e).
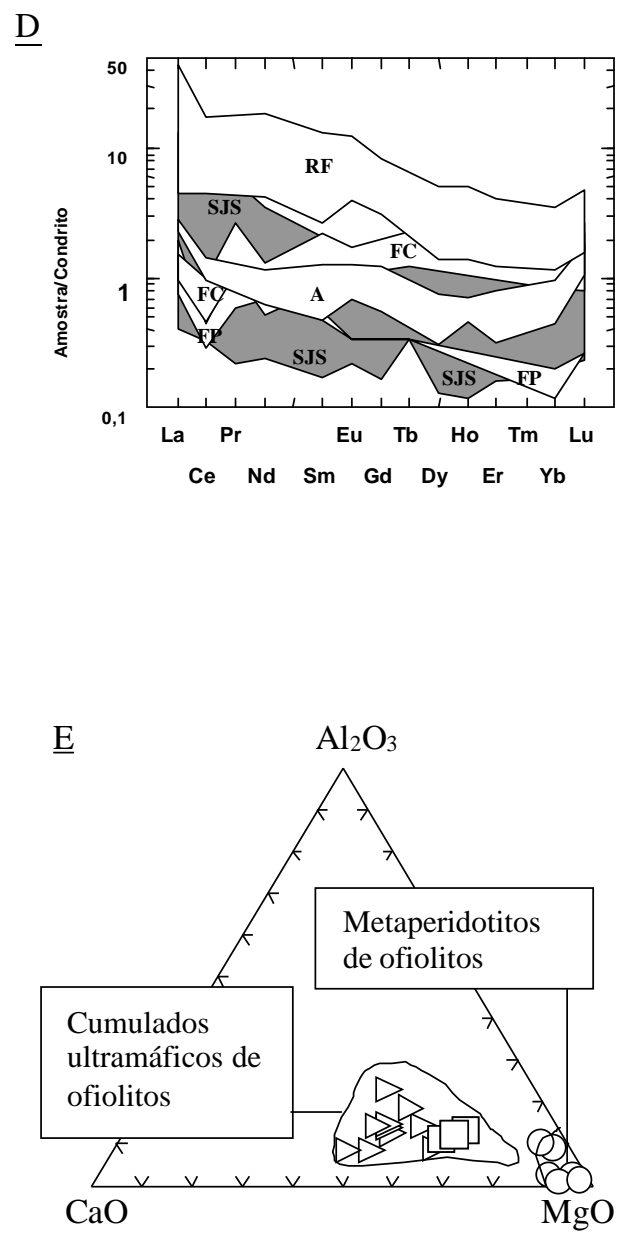

Figura 3: Diagramas geoquímicos representanto razões amostra/condrito nos eixos das ordenadas (A a D), normalizados pelo padrão de Evensen et al. (1978), e diagrama $\mathrm{Al}_{2} \mathrm{O}_{3}-\mathrm{CaO}-\mathrm{MgO}$. A, curvas multi-elementos para amostras de São José da Safira (círculos) e Ribeirão da Folha (triângulos). B, envoltórias das curvas multi-elementos de São José da Safira (SJS) e Ribeirão da Folha (RF). C, diagrama de elementos terras raras das amostras de São José da Safira. D, diagrama de elementos terras raras comparativo para amostras de São José da Safira (SJS), Ribeirão da Folha $(R F)$, Abadiânia (A), peridotitos (FP) e cumulados (FC) de Fuchuan. E, diagrama comparativo para metaperidotitos de São José da Safira (círculos), rochas meta-ultramáficas de Ribeirão da Folha (triângulos) e cumulados ultramáficos de Fuchuam (quadrados).

Figure 3: Geochemical diagrams showing sample/chondrite ratios (A to D), normalized according to Evensen et al. (1978), and $\mathrm{Al}_{2} \mathrm{O}_{3}-\mathrm{CaO}-\mathrm{MgO}$ diagram. A, spiderdiagram for samples of meta-ultramafic rocks from São José da Safira (circles) and Ribeirão da Folha (triangles). B, synoptic spiderdiagrams for São José da Safira (SJS) and Ribeirão da Folha $(R F)$ samples. $C$, rare earth element pattern of the São José da Safira meta-ultramafic rocks. D, rare earth element diagram comparing samples of meta-ultramafic rocks from São José da Safira $(\mathrm{SJS})$, Ribeirão da Folha $(\mathrm{RF})$, Abadiânia (A), and peridotites $(\mathrm{FP})$ and cumulates $(\mathrm{FC})$ from $\mathrm{Fuchuan}$. $\mathrm{E}, \mathrm{Al}_{2} \mathrm{O}_{3}$ $\mathrm{CaO}-\mathrm{MgO}$ diagram ilustrating correlations of metaperidotites from São José da Safira (circles), meta-ultramafic rocks from Ribeirão da Folha (triangles) and ultramafic cumulates from Fuchuam (squares). 


\section{CONCLUSÃO}

A geologia das áreas de São José da Safira e Ribeirão da Folha é muito semelhante. Ambas apresentam um ou mais corpos meta-ultramáficos tectonicamente encaixados numa sequência neoproterozóica que engloba xistos aluminosos, metachert, formações ferríferas bandadas, corpos de sulfetos maciços, grafita xisto e orto-anfibolito.

Entretanto, as rochas de São José da Safira apresentam restos da mineralogia e textura ígneas originais. Nos corpos meta-ultramáficos desta área identifica-se dois processos de alteração. O primeiro causou serpentinização e o segundo resultou na formação de talco + carbonato + antofilita.

Quimicamente, as rochas de São José da Safira e Ribeirão da Folha constituem dois conjuntos bem distintos em todos os diagramas. Ambos, entretanto, compartilham marcantes similaridades com outros ofiolitos neoproterozóicos.

\section{AGRADECIMENTOS}

Ao geólogo Sérgio Lima da Silva (CPRM-BH) pelas sugestões e cessão de mapas e textos. À geóloga Cibele T. de Carvalho pelo seu incentivo e cessão dos dados de Ribeirão da Folha. Às técnicas em química do Centro de Pesquisa Prof. Manoel Teixeira da Costa (CPMTCIGC-UFMG), Kácia M. M. Monteiro e Nívia R. V. de Mello, pelo seu apoio laboratorial. À FAPEMIG pelo suporte financeiro ao projeto "Transectos Geoeconômicos do Nordeste Mineiro" e ao CNPq pelas bolsas de iniciação científica e de produtividade em pesquisa. À Profa. Stelamaris de Oliveira Pinheiro pela revisão do trabalho.

\section{REFERÊNCIAS BIBLIOGRÁFICAS}

Aracema, L.W. 2000. Estudo petrográfico e geoquímico comparativo das rochas meta-ultramáficas das áreas de São José da Safira e de Ribeirão da Folha. Trabalho de Graduação, IGC/UFMG.

Aracema, L.W.; França, A.V.M.; Pedrosa-Soares, A.C.; Noce, C.M.; Ferreira, D.C. 1999. Granitóides cálcio-alcalinos do arco magmático neoproterozóico da Faixa Araçuaí: Evidências petrográficas e geoquímicas da região de Teófilo Otoni, MG, Brasil. In: SBGq, Congresso de Geoquímica dos Países de Língua Portuguesa, Porto Seguro, 5, Anais, 435-437

Carvalho, C.T.; Lobato, L.M.; Pedrosa-Soares, A.C. 1992. O corpo ultramáfico do Ribeirão da Folha, MG: Aspectos petrográficos e geoquímica da alteração hidrotermal. Revista Escola de Minas de Ouro Preto, 45: 170-172

CPRM-SGA 1997. Mapa magnetométrico da região entre $14^{\circ}-22^{\circ} 30^{\prime}$ $\mathrm{S}$ e $40^{\circ}-44^{\circ}$ W. Serviço de Geofísica Aplicada, Companhia de Pesquisa de Recursos Minerais, Belo Horizonte.

Cunningham, W.D.; Alkmim, F.F.; Marshak, S. 1998. A structural transect across the Coastal Mobile belt in the Brazilian Highlands (latitute $20^{\circ} \mathrm{S}$ ): the roots of a Precambrian transpressional orogen. Precambrian Research, 92: 251-275
Dobretsov, N.L.; Konnikov, E.G.; Dobretsov, N.N. 1992. Precambriam ophiolite belts of southern Siberia, Russia, and their metallogeny. Precambriam Research, 58: 427-446

Evensen, N.M.; Hamilton, P.J.; O'nions, R.K. 1978. Rare earth abundance in chondritic meteorites. Geochemical and Cosmochemical Acta 42: 1199-1212

Gass, I.G. 1990. Ophiolites and Oceanic lithosphere. In: J. Malpas, E.M. Moores, A. Panayiotou e C. Xenophontos (ed.) Ophiolites: Oceanic Crustal Analogues. Nycosia, Geological Survey Department of Cyprus, 1-12

Grossi-Sad, J.H., Lobato, L.M., Pedrosa-Soares, A.C.; Soares-Filho, B.S. (ed.) 1997. Projeto Espinhaço em CD-ROM. Belo Horizonte, Brazil, Companhia Mineradora de Minas Gerais

Henderson, P. 1984. Rare Earth Element Geochemistry. Amsterdam, Elsevier, $478 \mathrm{p}$.

Malpas, J.; Moores, E.M.; Panayiotou A.; Xenophontos, C. (ed.) 1990. Ophiolites: Oceanic Crustal Analogues. Nycosia, Geological Survey Department of Cyprus, 733p.

Molina, E.C.; Ussami, N.; Marangoni, Y.R. 2000. Digital 5'x5' Gravity Maps of the São Francisco Craton, the Marginal Fold/ Thrust Belts and Contiguous Continental Margin/Oceanic Basins. São Paulo, Instituto Astronômico e Geofísico, Universidade de São Paulo, CD-ROM.

Neves, A.C.; Ferreira, J.C.H. 1999. Mapeamento litoestrutural da Região de São José da Safira, Minas Gerais. Trabalho de Graduação, DEGEL-IGC-UFMG, 54 p. (vários anexos)

Pedrosa-Soares, A.C. (1997). Geologia da Folha Jenipapo. In: J. H. Grossi-Sad, L.M. Lobato, A.C. Pedrosa-Soares, B.S. SoaresFilho (ed.) 1997, Projeto Espinhaço em CD-ROM. Belo Horizonte, Companhia Mineradora de Minas Gerais

Pedrosa-Soares, A.C.; Vidal, Ph.; Leonardos, O.H.; Brito-Neves, B.B. 1998. Neoproterozoic oceanic remnants in eastern Brazil: Further evidence and refutation of an exclusively ensialic evolution for the Araçuaí-West Congo Orogen. Geology, 26: 519-522

Pedrosa-Soares, A.C.; Wiedemann-Leonardos, C.M. 2000. Evolution of the Araçuaí Belt and its connection to the Ribeira Belt, Eastern Brazil. In: U.G. Cordani, E.J. Milani, A. Thomaz-Filho, D.A. Campos (ed.), Tectonic Evolution of South America. Rio de Janeiro, IGC Brazil 2000, 265-285

Pedrosa-Soares, A.C.; Noce, C.M.; Wiedemann, C.M.; Pinto, C.P. 2001. The Neoproterozoic Araçuaí-West-Congo Orogen in Brazil: An overview of a confined orogen formed during Gondwana assembly. Precambrian Research, volume especial "Rodinia breakup and Gondwana assembly" (no prelo)

Pinto, C.P., Pedrosa-Soares, A.C., Wiedemann, C. 1998. Mapa geológico da porção brasileira do Orógeno Araçuaí-Oeste Congo. In: SBG, Congresso Brasileiro de Geologia, 40, Belo Horizonte. Anais: 37

Sengupta, S.; Ray, K.K.; Acharyya, S.K. e Smeth, J.B. 1990. Nature of ophiolite occurrences along the eastern margin of the Indian plate and their tectonic significance. Geology, 18: 439-442

Silva, S.L. 1997. Mapa Geológico da Folha Santa Maria do Suaçuí, escala 1:100.000. Projeto Leste, CPRM/COMIG

Strieder, A.J., Nilson 1992a. Mélange ofiolítica nos metassedimentos Araxá de Abadiânia (GO) e implicações tectônicas. Revista Brasileira de Geociências, 22: 204-215

Strieder, A.J., Nilson 1992b. Estudo petrológico de alguns fragmentos tectônicos da mélange ofiolítica de Abadiânia (GO): O protólito dos corpos de serpentinito. Revista Brasileira de Geociências, 22: $338-352$

Vernikovskiy, V.A.; Vernikovskaya, A.E.; Chernykh, A.I. 1998. Neoproterozoic Taymyr ophiolitic belts and opening of the PaleoPacific Ocean. International Geology Review, 40: 528-538

Zou, H.; Zhou, X.; Zhou, G. 1995. Geochemistry of a Precambriam Ophiolite from South China. Internacional Geology Review, 37: 623-635 